\title{
Proceeding
}

Supplementary Issue: Autumn Conferences of Sports Science. Costa Blanca Sports Science Events, 18-19 December 2020. Alicante, Spain.

\section{The research on the relationship between use motivation, target orientation and sports involvement in sports intelligent wearable equipment}

\author{
CHIN-CHENG YANG ${ }^{1}$, CHIH CHIEN SHEN², YU-SHENG LIN³ ${ }^{3}$ CHING-TE LIN³ \\ ${ }^{1}$ Department of Leisure Service Management, Chaoyang University of Technology, China \\ ${ }^{2}$ Yulin Normal University, Yulin, China \\ ${ }^{3}$ General Education Center, Chaoyang University of Technology, China
}

\begin{abstract}
The purpose of this study is to explore the impact of the use motivation of Sports Intelligent Wearable Equipment on target orientation and Sports involvement. Taking the users of sports intelligent wearable equipment as the research object, the researchers were asked to send questionnaires and network questionnaires, total of 400 questionnaires were issued, 385 valid questionnaires were collected, the effective recovery rate was $96.25 \%$. Data processing use descriptive statistics, independent sample t test, single factor variance analysis and multiple stepwise regression analysis. The research results are: first, male was mainly using the movement of intelligent wearable equipment: for the most age were 21 to 25 years old; most of the smart wear device price are below 1000. Second, different background variables in the use motivation, target orientation and sports involvement have significant differences exist. Third, the use motivations will positively affect the target orientation; the use motivation among the curiosity and epidemics will positively affect the sports involvement; target orientation will positively affect sports involvement.
\end{abstract}

Keywords: Intelligent wearable equipment; Target orientation; Sports involvement; Use motivation.

Cite this article as:

Yang, C-C., Shen, C.C., Lin, Y-S., \& Lin, C-T. (2021). The research on the relationship between use motivation, target orientation and sports involvement in sports intelligent wearable equipment. Journal of Human Sport and Exercise, 16(2proc), S434-S443. doi:https://doi.org/10.14198/jhse.2021.16.Proc2.29

Corresponding author. Department of Leisure Service Management, Chaoyang University of Technology, China.

E-mail: c researcher14@mail.ru

Abstract submitted to: Autumn Conferences of Sports Science. Costa Blanca Sports Science Events, 18-19 December 2020. Alicante, Spain.

JOURNAL OF HUMAN SPORT \& EXERCISE ISSN 1988-5202

(c) Faculty of Education. University of Alicante

doi:10.14198/jhse.2021.16.Proc2.29

S434 | 2021| Proc2 | VOLUME 16

C 2021 University of Alicante 


\section{INTRODUCTION}

According to the Ministry of Education Sports Department 2014 sports city survey results found, the domestic sports population has grown year by year. Hsiao and Wu 's (2003) pointed out that the regular exercise behaviour can make the muscles and joints, cardiovascular system and body composition, due to long-term exercise stimulation and get positive effects. In the psychological, also can reduce anxiety and depression, enhance positive emotions (Huang \& Ji, 2001). From the above we can understand that the regular exercise can make healthy, reduce the occurrence of disease and stress, the concept of the whole movement in this phenomenon came into being.

The rapid development of information technology, communications equipment and the popularity of wireless networks, so that more and more people use intelligent wearable equipment and mobile devices APP. Wear Technology provide long-term "portable" or "personal wear" function to use, the product contains a specific service function, which can be a long-time operation and allow the body to move freely or uninterrupted work. Modern electronic wearable products can be online or with a smart device or computer connection operations to extend the function of linkage, record management or access to cloud services. (Huang, 2015).

App is a "miniature application", the software industry has also introduced many different software for the users who love sports. Sports class App simple and easy to carry, not only to connect people, but also join the wisdom of health, medical, sports concept. The vast majority of sports class App has a variety of functions. Among the many functions, track record, data statistics and presentation, training plan is the most commonly used three functions.

According to the theory of cognitive evaluation (Deci \& Ryan, 1985), motivation can be divided into "intrinsic motivation" and "external motives". Intrinsic motivations are defined as individual participation activities for the activity itself and have fun and satisfaction from participation. The external motive is that the individual participates in the activity is external, not the interest or pleasure from the activity itself. But the external incentives, such as rewards, bonuses, medals and so on. Wei (2017) proposed that participants' motivation to participate has a positive correlation with the target orientation. And for the use of sports intelligence wearable equipment motives for the purpose of intrinsic motivation is recorded their own movement, change the concept of self-health and sports mode. Lin \& Shen \& Mao \& Yang (2019) do the research on sports APP found that the use motivation also has a positive impact on target orientation. While the external motives are chasing the trend, to show off the mentality or sports intelligence wearable equipment for social tools and so on.

According to the theory of target orientation theory (Dweck, 1986 \& Nicholls, 1989): the construction of the term of competence and the definition of success or failure, mainly using two different goals to judge. First is to compare with their past achievements to affirm self and achievement, hope to improve performance by training, it is called "work orientation". Second is the use of social comparison to define the achievements, people who have this psychological tendency hoping to show through the social comparison beyond the ability of others, it is called "self-orientation". Some recent studies have pointed out the differences in individual characteristics of target orientation is subject to personal sports training awareness, affection and the influence of society on personal success and achievement. Chen \& Hsieh \& Wang (2003) pointed out the motivations for the efforts to pursue progress in order to achieve the desired motivation, it can be seen that the motivation has a very close relationship with the target orientation. 
Venkartaman (1990) points out "sports involvement" is a continuation of the ongoing or keen on physical activity, while individuals continue to be involved in sports is strong against a particular sport, fascinated and made it a hobby. Chang (2008) also cited, to understand the relationship between sports motivation and involvement develop into ongoing activities and produce an activity that is motivated by internal motives. When an individual agrees with his or her goal, the main purpose is to achieve a designated or self-set goal, and thus improve the sports of individuals involved in behaviour. Many studies also confirm that there is a positive relationship between involvement and motivation(Amanda \& Meghan, 2015; Yang \& Liu \& Tang, 2015; Jamie \& Zhang \& Robin \& Meng, 2017; Ahmad \& Sahar, 2019; Ali \& Razi 2020).

In recent years, Taiwan's sports population has grown up, combine sports and modern information technology created the sports intelligent wearable equipment has set off a wave in the world. Because easy to carry and let people to live more convenient. It changed the way for our life, let more and more people use mobile devices and smart phones to surf the internet.

Therefore, this study explores the use motivation, target orientation and the sports involvement with using sports intelligent wearable equipment.

\section{Purposes of the study}

(A). To understand the sports intelligent wearable equipment's use motivation, target orientation and sports involvement status analysis.

(B). To explore the different background variables of the sports intelligent wearable equipment's use motivation, target orientation and sports involvement in differences situation.

(C). To explore the sports intelligent wearable equipment's use motivation, target orientation and sports involvement into the impact of the situation.

\section{Explain the operating terms}

(A). Sports Intelligent Wearable Equipment: This study refers sports intelligent wearable equipment can be a long time wearing or wearing a close use of the function, the product contains specific service functions, including wisdom, health, health, sports concepts, etc. to do sports work.

(B). Use of Motivation: Use of motivation refers to this study is to guide users to take action to meet their needs as a driving force; consumption is through the use of products rather than show themselves, so driven by the use of motivation to drive consumption we also summed up consumer motives in the use of motives.

(C). Target Orientation: Target orientation referred to in this study is that in the context of motion, for the subjective cognition of competence and success or failure. Mainly use two different goals to judge. First is to compare with their past achievements to affirm self and achievement, hoping to improve performance by train, it is called "work orientation". Second is the use of social comparison to define the achievements. Those who have this psychological tendency to hope to show through the social comparison beyond the ability of others, it is called "Self-orientation".

(D). Sports Involvement: Sports involvement was based on the fact that the subjects recalled the movement of the past seven days and were calculated according to the formula adopted by Fox (1987). Fox (1987) formula is: exercise participation $=$ motion frequency * (average intensity + exercise duration) to calculate the results. 


\section{METHOD}

In this study, intelligent wearable equipment users as the research object. The researchers were asked to send questionnaires and network questionnaires in January to February 2016 to conduct a formal questionnaire survey. Total of 400 questionnaires were issued, 385 valid questionnaires were collected. The effective recovery rate was $96.25 \%$.

This study was conducted on the use motivation, target orientation, sports involvement and personal background data variables for sports intelligence wearable equipment. Using SPSS for Windows 20.0 statistical suite software to do descriptive statistics, independent sample $t$ test (t-test), single factor variance analysis (one-way ANOVA) and multiple stepwise regression analysis statistical methods.

\section{RESULTS AND DISCUSSION}

\section{Situation analysis}

Sports intelligent wearable equipment users background variable in the status of the situation Male are 210 (54.5\%). The numbers of Aged up to 21 to 25 years old for 113 is the most (29.4\%). 105 people buy intelligence wearable equipment prices up to 1000 below is the most. (27.3\%).

Analysis the use motivations, target orientation and sports involvement of using sports intelligence wearable equipment users. Use motivations scale total has four facets, the results show that the whole use motivation showed a moderate degree of cognitive situation ( $M=3.64, S D=0.54)$. "Practical and functional" factors were the highest $(M=4.36, S D=0.65)$, second is "informality" ( $M=3.68, S D=0.76)$, then is "recreational leisure" ( $M=3.60, S D=0.81)$, and the "curiosity and epidemic" is the lowest $(M=3.37, S D=0.93)$. Indicating that the utility function is more attractive to the sport's intelligent wearable equipment users, and because of curiosity and popular to use people are less.

Target orientation scale total has three facets, the results showed that target orientation showed a moderate degree of cognition $(M=3.58, S D=0.67)$. The "affection" factors the highest awareness $(M=3.98, S D=$ $0.68)$, second is "cognition" $(M=3.61, S D=0.84)$, the "society" is lowest $(M=3.32, S D=0.84)$. Indicates the users who want to get fun and the establishment of personal self-confidence is more. Users who want to know friends and enrich the personal social life are fewer.

Sports involvement arrangement from high to low, divided into "high participation", which scores between 40 60. "Degree of participation" with a score of 21-39; "low participation" with a score of 2-20. High degree of participation has 35 people, is the least. Degree of participation accounted for 138 people, low participation has 212 people, which is the most. The results of the study found that the use of sports intelligence wearable equipment users will participate in sports, but the majority of people with low participation.

Different background variables of the sport's intelligent wearable equipment users between use motivation, target orientation and sports involvement in difference situation

(A) Different background variables of the sports intelligent wearable equipment users in the use motivation of the differences

Gender factor

Different gender in the use motivation after single factor analysis of the results found that the facet are not significant differences. Indicating that the user will not be different from the gender in the use of motivational differences exist. According to Lin \& Shen \& Mao \& Yang (2019) study that pointed out male use motivation 
is higher than female in use sports APP. But in this study, sports intelligent wearable equipment is to use as a personal status to do. With the other opinion, sports intelligent wearable equipment needs to spend money to buy it, users pay to buy it is to use. So, the sports intelligent wearable equipment will not have differences between men and women.

Age factor

At different ages, there is a significant level of "recreational recreation" and "curiosity and epidemic" in the use motivation. As a result of the Scheffe post hoc comparison, no difference exists. It is means that the user wearing the equipment will not be different from the age in the use motivation there are differences in the situation exists. We have same result with Lin \& Shen \& Mao \& Yang (2019) study. Researchers believe that the age factor because of the young ethnic groups is the most, they pay more attention to life on the entertainment and follow the trend, so they have a higher willingness to use sports intelligence wearable equipment.

Price factor

Different prices in the use motivation's "information" significant difference. After the results by Scheffe post hoc comparison, the price more than NT 7,000 more than NT 5,001 NT 7,000 of sports intelligence wearing device users. Researchers believe that the group more than NT 7,000 in the selection of sports intelligence wearable equipment have higher requirements of information. In contrast, lower prices group do not pay attention on information. As shown in Table 1.

Table 1. ANOVA summary table for different prices in use motivation

\begin{tabular}{lllllll}
\hline $\begin{array}{l}\text { Use } \\
\text { motivation }\end{array}$ & Price & $\begin{array}{l}\text { The } \\
\text { number of } \\
\text { people }\end{array}$ & Average & $\begin{array}{l}\text { Standard } \\
\text { deviation }\end{array}$ & $\begin{array}{l}\text { F- } \\
\text { value }\end{array}$ & $\begin{array}{l}\text { Scheffe post } \\
\text { hoc comparison }\end{array}$ \\
\hline \multirow{5}{*}{ Informative } & A.Lower than NT 1000 & 105 & 3.63 & .77 & & \\
& B.NT 1001 NT 3000 & 97 & 3.64 & .69 & & \\
& C.NT 3001 NT 5000 & 67 & 3.58 & .74 & $3.71^{*}$ & E >D \\
& D.NT 5001 NT 7000 & 35 & 3.41 & .79 & & \\
& E. Higher than NT 7001 & 81 & 3.94 & .75 & & \\
\hline \multicolumn{7}{c}{ Note: ${ }^{*} p<.05}$.
\end{tabular}

(B) Different background variables of the sports intelligent wearable equipment users in the target orientation of the differences situation

Gender factor

Different gender in the target orientation through single factor analysis of the results of variance, found that the faceted were not significantly different, it means that the user of the sports intelligent wearable equipment does not have a difference in the target orientation due to the difference in gender. According to Chen \& Liang (2014) research, also found that the target orientation does not exist in different gender. Researchers believe that the main purpose of personal identification of goals is to achieve the goal, and vary from person to person, therefore unrelated with gender.

Age factor

At different ages, the results of single factor variance analysis showed that the facets were not significantly different. It means the user of the sports intelligent wearable equipment does not have a difference in the target orientation due to age. According to Lin \& Shen \& Mao \& Yang (2019) research, also found that the 
target orientation does not exist in different age. The researchers believe that each age cannot achieve the same goal, so the age in the target orientation will not be different.

Price factor

Different price in the target orientation after a single factor analysis of the results found that the facet are not significant differences. It is indicated that the user of the sports intelligent wearable equipment does not have a difference in the target orientation due to the difference in the price. Researchers believe that individuals are different for the target. In order to achieve the goal, regardless of the price of the device will be buy, so the price of sports intelligence wearable equipment in the target orientation does not exist differences.

(C) Different background variables of the sports intelligent wearable equipment in sports involvement in the difference situation

Gender factor

Different gender in sports involvement has significant differences. Indicating that the sports intelligent wearable equipment users have different in sports involvement in different gender. The results of the study are similar the study of Chou and Chang (2014). Based on past domestic research, sports involvement is male higher than female. As shown in Table 2.

Table 2. ANOVA summary table for different prices in target orientation.

\begin{tabular}{llccccc}
\hline Factor facets & Gender & Numbers & Average & Standard deviation & t value & $p$-value \\
\hline \multirow{2}{*}{ Sports involvement } & Male & 210 & 24.48 & 13.25 & \multirow{2}{*}{6.288} & \multirow{2}{*}{00} \\
& Female & 175 & 16.82 & 10.03 & & \\
\hline
\end{tabular}

Age factor

Different age in the sports involvement significant differences, as a result by Scheffe post hoc comparison, does not exists difference. The results of the study are different with Tsai and Chen's (2008) studies. Researchers believe that for those who have a habit of exercise will not stop their exercise habit because of their age changes. So, there is no difference in sports involvement of different ages.

Price factor

Different prices in sports involvement use single factor analysis of the results found that the facet is not significant differences. It means the user of sports intelligent wearable equipment does not have a difference in sports involvement due to the difference in the price of the sport's intelligent wearable equipment. Researchers believe that the sports intelligent wearable equipment is only to assist athletes to exercise, the price will not affect their exercise frequency. So, there is no difference in different price of sports intelligence wearable equipment in sports involvement.

\section{Sports intelligent wearable equipment relationship of use motivation, target orientation and sports involvement}

(A) The impact analysis of use motivation to the target orientation

The results of the analysis are shown in Table 3 . To predict the target orientation using the motivational facets, "informality" ( $t=8.764, p<.05)$, "entertainment and leisure" $(t=3.485, p<.05)$, and "curiosity and effort" ( $t=3.019, p<.05)$, these three facets up to a significant level, the variance of the three variables is $27.7 \%$, the "information" to explain is the best, its interpretation of the amount of $22.9 \%$. The normalized regression coefficients are respectively $.404, .158, .139$. Which means the motive of the sports intelligent wearable equipment can effectively predict the target orientation. This result is match with Lin \& Shen \& Mao \& Yang (2019) and Lai (2004) results. Researchers believe that the use of sports intelligence wearable 
equipment is an entertaining leisure activity, also can bring fun for life, and get the right concept of exercise, so that the body and mind to achieve a perfect development.

Table 3. Step-by-Step regression analysis of the use motivations for target orientation.

\begin{tabular}{lllllll}
\hline $\begin{array}{l}\text { Dependent } \\
\text { variable }\end{array}$ & $\begin{array}{l}\text { Input variable } \\
\text { sequence }\end{array}$ & $\begin{array}{l}\text { Multiple } \\
\text { correlation } \\
\text { coefficient } \\
\mathbf{( R )}\end{array}$ & $\begin{array}{l}\text { Coefficient of } \\
\text { determination } \\
\left(\mathbf{R}^{2}\right)\end{array}$ & F value & $\begin{array}{l}\text { Standardized } \\
\text { regression } \\
\text { coefficients }\end{array}$ & $\boldsymbol{t}$ value \\
\hline \multirow{2}{*}{$\begin{array}{l}\text { Target } \\
\text { orientation }\end{array}$} & $\begin{array}{l}\text { Informality } \\
\text { Entertainment } \\
\text { and leisure }\end{array}$ & .478 & .229 & 113.668 & .404 & $8.764^{* *}$ \\
& $\begin{array}{l}\text { Curiosity and } \\
\text { effort }\end{array}$ & .509 & .259 & 66.848 & .158 & $3.495^{* *}$ \\
\hline & & & .277 & 48.550 & .139 & $3.019^{* *}$ \\
\hline
\end{tabular}

(B) The impact analysis of use motivation to sports involvement

The results of the analysis are shown in Table 4. Use the use motivation fractal to predict the movement involved, "curious and epidemic" ( $t=2.007, p<.05)$ facets up to a significant level, it is means $1 \%$ of the sports involvement will be affected by the "curious epidemic". The normalized regression coefficient is .102. That is, the use of sports intelligence wearable equipment users motivated "curious epidemic" is higher, sports involvement will higher. This result is match with Lai (2004) results. Researchers believe that the user of sports intelligence wearable equipment have practical exercise behaviour, and because this device brings fashionable, novel, and modern psychological feelings, that will be able to improve the sports involvement.

Table 4. Step-by-Step regression analysis of the use motivation for sports involvement.

\begin{tabular}{|c|c|c|c|c|c|c|}
\hline $\begin{array}{l}\text { Dependent } \\
\text { variable }\end{array}$ & $\begin{array}{l}\text { Input } \\
\text { variable } \\
\text { sequence }\end{array}$ & $\begin{array}{l}\text { Multiple } \\
\text { correlation } \\
\text { coefficient (R) }\end{array}$ & $\begin{array}{l}\text { Coefficient of } \\
\text { determination } \\
\left(R^{2}\right)\end{array}$ & $\begin{array}{l}\mathbf{F} \\
\text { value }\end{array}$ & $\begin{array}{l}\text { Standardized } \\
\text { regression } \\
\text { coefficients }\end{array}$ & $\begin{array}{l}t \\
\text { value }\end{array}$ \\
\hline $\begin{array}{l}\text { Sports } \\
\text { involvement }\end{array}$ & $\begin{array}{l}\text { Curious and } \\
\text { epidemic }\end{array}$ & .102 & .010 & 4.207 & .102 & $2.007^{*}$ \\
\hline
\end{tabular}

Note: ${ }^{*} p<.05$

(C) The impact analysis of target orientation on sports involvement

Table 5. Summary of step-by-step regression analysis for target orientation to sports involvement.

\begin{tabular}{lllcccc}
\hline $\begin{array}{l}\text { Dependent } \\
\text { variable }\end{array}$ & $\begin{array}{l}\text { Input variable } \\
\text { sequence }\end{array}$ & $\begin{array}{l}\text { Multiple } \\
\text { correlation } \\
\text { coefficient(R) }\end{array}$ & $\begin{array}{l}\text { Coefficient of } \\
\text { determination } \\
\left(\mathbf{R}^{2}\right)\end{array}$ & F value & $\begin{array}{l}\text { Standardized } \\
\text { regression } \\
\text { coefficients }\end{array}$ & t value \\
\hline \multirow{2}{*}{$\begin{array}{l}\text { Sports } \\
\text { involvement }\end{array}$} & Cognition & .112 & .013 & 4.886 & .134 & $2.176^{*}$ \\
& Society & .160 & .025 & 4.993 & .185 & $2.908^{*}$ \\
& Affection & .191 & .036 & 4.787 & .134 & $2.071^{*}$ \\
\hline
\end{tabular}

The results of the analysis are shown in Table 5. The target orientation fractal is used to predict the sports involvement, "cognition" ( $t=2.176, p<.05)$, "society" ( $t=2.908, p<.05)$, "affection" ( $t=2.071, p<.05)$, these three facets are not to significant level. Three variables were combined to explain the variance of $3.6 \%$. Which the "cognition" explains the best, its interpretation of $1.3 \%$. The normalized regression coefficients were $1.134, .185, .134$, it means the user of sports intelligent wearable equipment's target orientation is high, the sports involvement is higher. The results are in match with Chen and Liang's (2014) results. Researchers 
believe that when people agree with the goal, and achieve self-set goals, that will raise personal sports involvement.

\section{CONCLUSIONS}

Demographic variables and the status of the use of motivation, target orientation and sports involvement

Demographic variables

Males are $210(54.5 \%)$. The numbers of Aged up to 21 to 25 years old for 113 is the most (29.4\%). 105 people buy intelligence wearable equipment prices up to 1000 below is the most. (27.3\%).

The Situation of Use Motivation, Target Orientation and Sports Involvement. In Use Motivation's facet, the highest score is "utility and functionality"; second is "information", third is "entertainment and leisure", "curiosity and epidemic" is the lowest. Sports involvement's number by distribution analysis showed sports intelligence wearable equipment users are engaged in sports. High participation of 40-60 points have 35 people is the minimal, in the degree of participation 21-39 points for 138 people, low participation level of 220 points have 212 people is the most. In target orientation each facet score, the highest score is "affection", second is "cognition"; the lowest score is "society".

Different background variables of the sport's intelligent wearable equipment users between use motivation, target orientation and sports involvement in difference situation

Use motivation

Different background variables of sports intelligent wearable equipment user have significantly different on the prices, but has no significant differences exist on gender and age.

\section{Target orientation}

Different background variables of sports intelligent wearable equipment user have no significant differences exist on price, gender and age.

Sports involvement

Different background variables of sports intelligent wearable equipment user have significantly different on gender, but has no significant differences exist on price and age.

The impact of situation on sports intelligence wearable equipment use motivation, target orientation and sports involvement

Use motivation will positively affect target orientation. Use motivation's facets "curiosity and epidemic" will positively affect sports involvement. Target orientation will positively affect sports involvement.

\section{RECOMMENDATIONS}

\section{Sports technology industry}

The results of this study found that in target orientation, users have a high "affection" awareness, less "social" cognition. Which means that users use sports intelligence wearable equipment has no group of social feelings, so that the manufacturers can be added some function, such as a cell phone shake function, help the users make some same habit friends. The results of the study found that in target orientation, users pay more attention on "practical and functional", Compared with the "curiosity and epidemic". Practical and functional emphasis on easy to carry, convenient and available functions, can improve the quality of life as a 
life helper. Sports technology industry should be more focus on "practical and functional", strengthen the practical value of the product. In modern society, people began to pay attention on their body health. For example, to detect or monitor the body fat signal showing the obesity coefficient of the human body, through the equipment to be displayed, store records, so that people can measure directly with the equipment.

\section{Sports intelligence wearable equipment sales unit}

The results found that sports intelligence wearable equipment users most are college students and male. So that the sports intelligence wearable equipment sales unit can work with famous sports-style female artist endorsement sports intelligent wearable equipment, through advertising, newspapers and magazines, improve sports intelligent wearable equipment exposure. That consumer's motivation can be improving; through the endorsement way can increase the sports intelligence wearable equipment topic, improve consumer concerns by the news media exposure. When consumers buy sports, intelligent wearable equipment can immediately participate in the draw game, increase consumers purchase intention then increase the purchase volume.

\section{Sports related units}

The results of this study found that the sports intelligent wearable equipment users have the low sports involvement are 212 people, which is the most. In order to promote the national sports, use by the wearing device pedometer function and cooperate with the relevant sporting goods business, to accumulate the number of steps to exchange for discount, it can attract people achieve sports fitness and help people's health. The most important is raise people's sports involvement.

\section{REFERENCES}

Ahmad, I., Sahar. (2019). Waste Management Analysis From Economic Environment Sustainability Perspective. International Journal Of Scientific \& Technology Research 8(12), 1540-1543.

Ali, S., \& Razi, M. (2020). An Analytical Study of Pre-Trial Processes in Speedy Disposal of Cases in the Criminal Justice System of Malaysia. International Journal of Criminology and Sociology, 9, 9-15. https://doi.org/10.6000/1929-4409.2020.09.02

Amanda, J.R., \& Meghan, H.M.. (2015). Moderated and mediated effects of coach autonomy support, coach involvement, and psychological need satisfaction on motivation in youth soccer. Human Kinetics Journals, 29(1). https://doi.org/10.1123/tsp.2014-0023

Chang, X.-M. (2008). Leisure Consumer Behavior. Taipei, Hwa-Du bookstore.

Chen, C- C., Hsieh, J.-W., \& Wang, C.-L. (2003). The Effects of Sport Achievement Motivation and Goal Orientation on Sport Learning Performance and Intrinsic Motivation. Journal of Physical Education, 361-370.

Chen, L.-S., \& Liang, S.-C. (2014). The Research on Sports Goal Identity of High School Students in Tao-Yuan High School and Yung-Feng high school in Tao-Yaun Area. NCYU. Journal of Physical Education, Health \& Recreation, 7(2), 43-51.

Chou, C.-S., \& Chang, P.-T. (2014). The research of Leisure Sports participation, Sports Involvement and Social Support. Journal of Review of Leisure, Sport and Health, 5(2), 63-77.

Deci, E. L., \& Ryan, R. M. (1985). Intrinsic motivation and the self-determination in human behavior. New York, NY:Plenum Press. https://doi.org/10.1007/978-1-4899-2271-7

Dweck, C. S. (1986). Motivational processes affecting learning. American psychologist,41(10),1040. https://doi.org/10.1037/0003-066X.41.10.1040

Fox, K. R. (1987). Physical self-perceptions and exercise involvement. Arizona State University. 
Hsiao, S.-F., \& Wu, T.-E. (2003). The research and analysis of Central Police University Students Exercise Behavior and Health Fitness. TamKang Sports, 6, 97-101.

Huamg, Y.-Z., \& Ji, L.-K. (2001). The strategy and methods to train good exercise habit behavior's of changes. The University Physical Education and Sports, 53, 87-93.

Huang, W- Z. (2015). Intelligence Wearing Product Design Develop and Opportunity. Market Intelligence \& Consulting Institute and Institute for Information Industry.

Jamie A. Levitt, Pei Zhang, Robin B. Dipietro \& Fang Meng. (2017). Food tourist segmentation: attitude, behavioral intentions and travel planning behavior based on food involvement and motivation. International Journal of Hospitality \& Tourism Administration. 1-27. https://doi.org/10.1080/15256480.2017.1359731

Lai, Y.-H. (2004). An Exploratory Study of VOIP Using Behaviors : Focus on VOIP Innovation Attributes, Using Motivation and Gratification. (Unpublished master thesis, National Chiao Tung University, Hsinchu, Taiwan). (in Chinese).

Lin, C. T. and Shen, C. C. and Mao, T. T. and Yang, C. C. (2019). Study on the Influence of Use Motivation and Target Orientation of Sports APP on Sports Behavior. Polish Journal of Management Studies, 19(1), 225-234. https://doi.org/10.17512/pims.2019.19.1.17

Nicholls, J.G. (1989). The competitive ethos and democratic education! Cambridge, MA: Harvard University Press.

Tsai, T.-C., \& Chen, H.-C. (2008). The Research of Billiards Sports Consumer's Sports Involvement in Yun-Lin, Chia-Yi, Tainan area. NCYU journal of Physical Education, Health \& Recreation, 7(3), 71 80.

Venkatraman, M. P., \& Price, L. L. (1990). Differentiating between cognitive and sensory innovativeness: Concepts, measurement, and implications. Journal of Business Research, 20(4), 293-315. https://doi.org/10.1016/0148-2963(90)90008-2

Wei, C. E. (2017). Research on Sport Goal Orientation and Participation Motivation of Football Game Participants. Sports Coaching Science, 47, 27-37.

Yang, C.-C., Liu, L.-W., Tang, S.-K. (2015). The Study on Flying Disc Participants' Motivation, Involvement, and Flow Experience. Chung Yuan Physical Education Journal, 6, 105-117.

\section{@(@) $\Theta \Theta$}

This work is licensed under a Attribution-NonCommercial-NoDerivatives 4.0 International (CC BY-NC-ND 4.0). 